\title{
Cathodic Protection of Mild Steel and Some Copper Alloys in Moving Artificial Sea Water
}

\author{
Hayata Shigeno and Toyoji KoBAYASHI*
}

Many reports concerning minimum current density required for complete cathodic protection of metals in sea water have been made, but most of them were measured under stagnant or low flow velocity conditions. Therefore, there are increasing demands for data obtained under high flow velocity condition. The purpose of this study is to examine the corrosion of mild steel, brass, gun metal, manganese bronze, and the protective effects of cathodic current on these alloys under moving states with the velocities of 3.3 and $5.3 \mathrm{~m} / \mathrm{sec}$, and further to determine the requirements for protection.

(b) Specimen

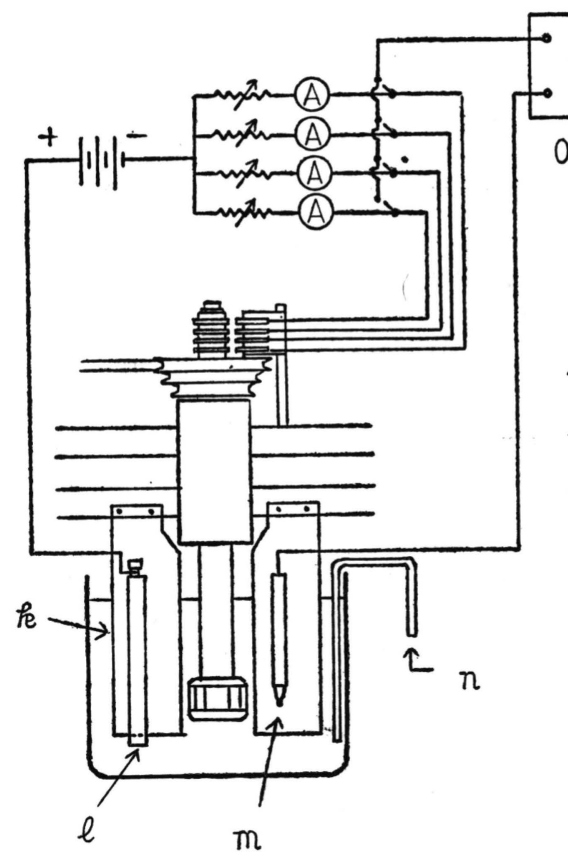

(a) Experimental apparatus and electric circuit

k : Bakelite baffle plate

e : Carbon anode

$\mathrm{m}$ : Saturated calomel elctrode

$\mathrm{n}$ : Washing bottle and air bomb

o : Vacuum tube voltometer

p : Bakelite armored shaft
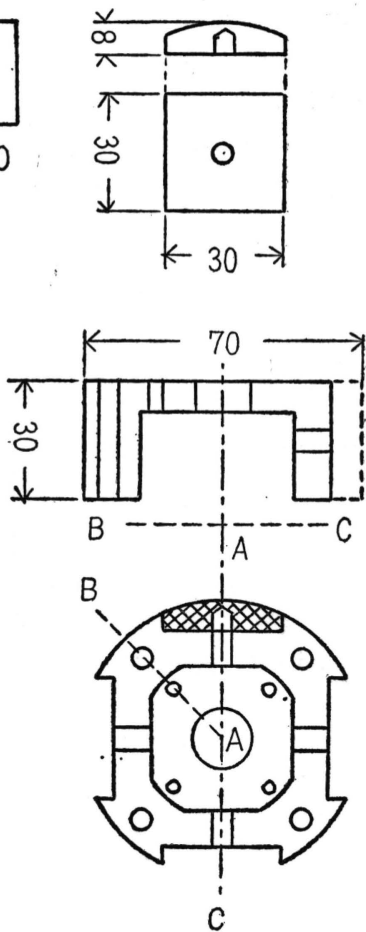

(c) Specimen holder (bakelite)

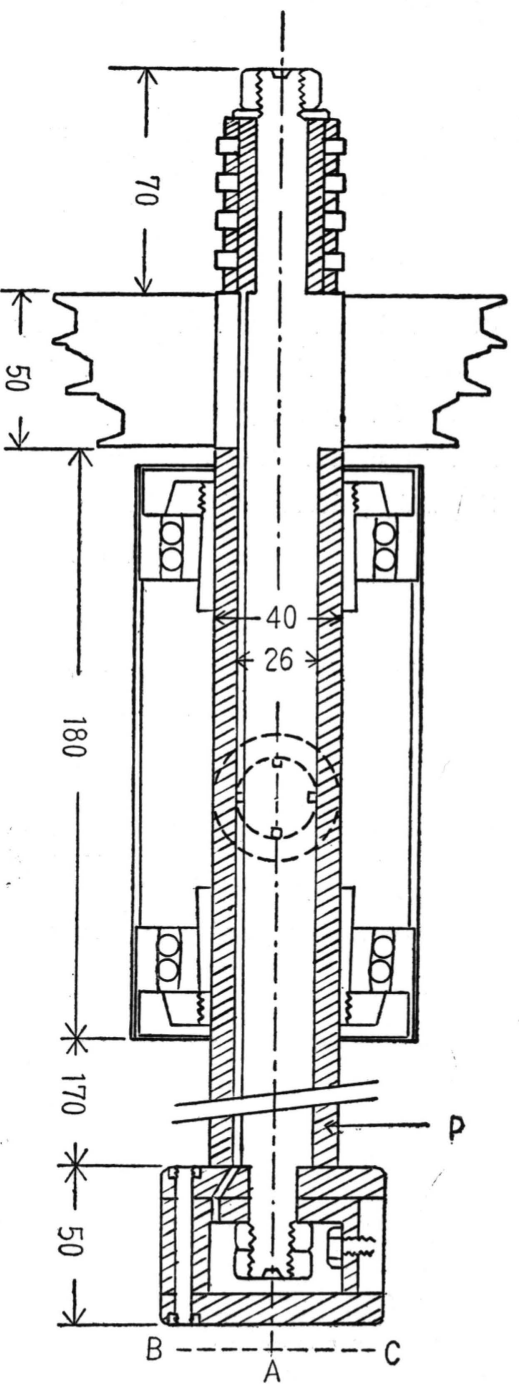

(d) Rotor test apparatus

Fig. 1 Experimental apparatus. 
Experiments were carried out in aerated artificial sea water at $25^{\circ} \mathrm{C}$ by high speed rotor test(1) apparatus illustrated in Fig. 1. The results obtained ware summarized as follows :

(1) The corrosion rate of every alloy increased remarkably under moving states as compared with stagnant one as shown in Table 1 . The corrosion potential of mild steel was more noble in moving Table 1 Mean Corrosion Rates in Moving Artificial Sea Water.

$$
25 \sim 30 \mathrm{hr}\left(\mathrm{g} / \mathrm{m}^{2} \text {. hr. }\right)
$$

\begin{tabular}{c|c|c|c|c}
\hline \hline $\begin{array}{c}\text { Velocity } \\
(\mathrm{m} / \mathrm{sec})\end{array}$ & Mild Steel & Brass & Gun metal & Mn bronze \\
\hline 5.3 & 2.3 & 1.5 & 0.40 & 0.69 \\
3.3 & 1.7 & 0.46 & 0.35 & 0.53 \\
0 & 0.35 & 0.043 & Weight gain & Weight gain \\
\hline
\end{tabular}

states than when stagnant, while those of copper alloys were less noble, as shown in Table 2 . It may be considered in case of these phenomena that mild steel, the depolarizing action of oxygen

Table 2 Corrosion Potentials in Moving Artificial Sea Water. ( $\mathrm{mV}$ against saturated calomel electrode)

\begin{tabular}{c|c|c|c|c}
\hline \hline $\begin{array}{c}\text { Velocity } \\
(\mathrm{m} / \mathrm{sec})\end{array}$ & Mild Steel & Brass & Gun metal & Mn bronze \\
\hline 5.3 & -548 & -250 & -250 & -238 \\
3.3 & -578 & -235 & -235 & -228 \\
0 & -712 & -229 & -207 & -179 \\
\hline
\end{tabular}

dissolved in water is accelerated by movement, and that in the case of copper alloy, the oxide film is removed and the concentration of copper ion adjacent to metal surface decreases by movement.

(2) Every alloy can be protected almost completely by supplying cathodic current even under moving states. The minimum current densities necessary to give complete protection determined by the weight losses of specimens as shown in Table 3.

Table 3 Minimum Current Densities Required for Complete Cathodic Protection $\left(\mathrm{A} / \mathrm{m}^{2}\right)$.

\begin{tabular}{l|c|c}
\hline \hline \multirow{2}{*}{ Materials } & \multicolumn{2}{|c}{ Velocities (m/sec.) } \\
\cline { 2 - 3 } & 5.3 & 3.3 \\
\hline Mild Steel & 5.5 & 3.5 \\
Brass & 1.0 & 0.7 \\
Gun metal & 0.6 & 0.4 \\
Mn Bronze & 0.4 & 0.2 \\
\hline
\end{tabular}

(3) If the protected steel surface is coated prior to work with calcareous deposits by the so-called electrocoating method, the current requirement can be greatly reduced as shown in Table 4 .

Table 4 Effects of Electrocoating on Mild Steel

\begin{tabular}{c|c|c}
\hline \hline $\begin{array}{c}\text { Protecting Current Density } \\
\left(\mathrm{A} / \mathrm{m}^{2}\right)\end{array}$ & $\begin{array}{c}\text { Mean Corrosion Rate } \\
\left(\mathrm{g} / \mathrm{m}^{2} . \mathrm{hr} .\right)\end{array}$ & $\begin{array}{c}\text { Rate of Protection* } \\
(\%)\end{array}$ \\
\hline 0.20 & 0.0086 & 99.6 \\
0.05 & 0.0129 & 99.5 \\
0.02 & 0.0300 & 98.7 \\
No. electrocoating & 2.38 & - \\
\hline
\end{tabular}

* Rate of protection was calculated in comparison with the mean corrosion rate without electrocoating.

(4) Protective potentials were about $-350 \mathrm{mV}$ for copper alloys and- $770 \mathrm{mV}^{(2)}$ for mild steel referred to a saturated calomel electrode.

(Received April 30, 1958)

\section{Literature :}

(1) F. Wormrwell, T.J. Nurse, H.C.K. Iron : J. Iron Steel Inst., 160, 247 (1948)

(2) H. Shigeno, T. Kokayashi : Rept. Gov. Chem. Res. Inst., Tokyo : 50, 361 (1955) 